\title{
Detection and Characterization of Listeria monocytogenes in São Jorge (Portugal) Cheese Production
}

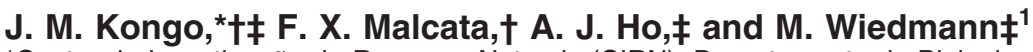 \\ ${ }^{*}$ Centro de Investigação de Recursos Naturais (CIRN), Departamento de Biologia, Universidade dos Açores, Ponta Delgada, Açores, Portugal \\ †Escola Superior de Biotecnologia, Universidade Católica Portuguesa, Porto, Portugal \\ ¥Department of Food Science, Cornell University, Ithaca, NY 14853
}

\section{ABSTRACT}

Listeria monocytogenes is a foodborne pathogen that can cause serious invasive disease in humans. Because human listeriosis cases have previously been linked to consumption of contaminated cheese, control of this pathogen throughout the cheese production chain is of particular concern. To understand the potential for $L$. monocytogenes transmission via São Jorge cheese, a Portuguese artisanal cheese variety that bears a Protected Denomination of Origin classification, 357 raw milk, curd, natural whey starter, and cheese samples representative of the production chain of this cheese were collected over one year and tested for the presence of $L$. monocytogenes and selected physicochemical parameters. Although neither L. monocytogenes nor other Listeria spp. were detected in whey, curd, or cheese samples, 2 of the 105 raw milk samples analyzed were positive for $L$. monocytogenes. These 2 raw milk isolates represented a ribotype that has previously been linked to multiple human listeriosis outbreaks and cases elsewhere, indicating the potential of these isolates to cause human listeriosis. On average, physicochemical parameters of São Jorge cheese ripened for 4 mo presented values that likely minimize the risk of $L$. monocytogenes outgrowth during ripening and storage (mean $\mathrm{pH}=$ 5.48 ; mean moisture $=37.79 \%$; mean $\mathrm{NaCl}$ concentration $=4.73 \%$ ). However, some cheese samples evaluated in this study were characterized by physicochemical parameters that may allow growth and survival of $L$. monocytogenes. Even though our results indicate that raw milk used for São Jorge cheese manufacture as well as finished products is rarely contaminated with L. monocytogenes, continued efforts to control the presence of this pathogen in the São Jorge cheese production chain are urged and are critical to ensure the safety of this product.

Key words: Listeria monocytogenes, Azores, cheese, food safety

Received February 22, 2006.

Accepted May 28, 2006.

${ }^{1}$ Corresponding author: mw16@cornell.edu

\section{INTRODUCTION}

Listeria monocytogenes is a gram-positive opportunistic pathogen that has been isolated from many natural and human-created environments. Human listeriosis is a primarily foodborne infection that occurs predominantly in elderly and immunocompromised people, as well as in pregnant women (Low and Donachie, 1997; Mead et al., 1999). Clinical symptoms of invasive listeriosis include septicemia, encephalitis, and meningitis, as well as miscarriage in pregnant woman. In addition, listerial gastroenteritis in immunocompetent hosts has been reported (Dalton et al., 1997; Fsihi et al., 2001). Even though listeriosis is a rare disease, invasive human foodborne listeriosis represents a considerable public health concern because of its high case mortality rate of about 20\% (Mead et al., 1999). Listeria monocytogenes also causes disease in dairy cattle, including abortions and central nervous system infections, and is commonly isolated from dairy farm environments and fecal material from dairy cattle (Husu, 1990; Nightingale et al., 2004).

Most human listeriosis cases appear to be linked to consumption of ready-to-eat (RTE) food products that have undergone listeriocidal heat treatments but have been contaminated postprocessing from environmental sources. However, some cases and outbreaks have been linked to consumption of food products that did not undergo heat treatment and appear to have been contaminated by on-farm sources (Lundén et al., 2004). In particular, L. monocytogenes contamination of fermented dairy products made from raw milk may be due either to use of contaminated raw milk or to postprocessing contamination from environmental sources not directly linked to raw milk (Broseta et al., 2003; Kells and Gilmour, 2004). For example, a human listeriosis outbreak linked to consumption of contaminated Hispanic-style cheese may have been caused by the use of $L$. monocytogenes-contaminated raw milk in cheese making (Linnan et al., 1988; Ryser, 1999).

Measures are taken and regulations enforced in most countries to reduce contamination of RTE foods with L. monocytogenes. Italy and the United States, for ex- 
ample, have a so-called "zero tolerance" policy for the presence of $L$. monocytogenes in RTE foods, meaning that this species must be absent from a 25 -g food sample. Other countries, which consider such a goal of "zero tolerance" to be difficult to comply with, have standards that limit the presence of $L$. monocytogenes up to a maximum of $100 \mathrm{cfu} / \mathrm{g}$ in certain foods (Pagotto et al., 2002). Listeria monocytogenes control measures recommended by the Health and Consumer Protection Directorate of the European Commission include, among others, hygiene practices, risk communication, and consumer education (European Commission, 1999). However, this group considers the product profile to be a critical point for preventive measures against $L$. monocytogenes. Specifically, stringent control measures are required for RTE foods that potentially permit growth of $L$. monocytogenes, such as foods with high $\mathrm{pH}$ or high water activity $\left(\mathbf{a}_{\mathbf{w}}\right)$, particularly if these RTE foods did not receive any listeriocidal (e.g., pasteurization) treatment (European Commission, 1999). The requirements of these control measures are consistent with various studies (Adams and Nicolaides, 1997; European Commission, 1999) showing that L. monocytogenes can grow to high levels in foods stored at refrigerating temperatures, even though the pathogen is generally a poor competitor that can easily be overgrown by other psychrotolerant or psychrophilic bacteria present in foods.

As stressed above, consumption of $L$. monocytogenescontaminated cheeses has been linked to a number of human listeriosis outbreaks (Linnan et al., 1988; Adams and Moss, 1995b; Ryser, 1999; Boggs et al., 2001). Artisanal cheeses produced with raw milk in small dairy farms or small processing operations may be at particular risk for L. monocytogenes contamination because of the lack of heat treatment of the raw materials, as well as because of the potentially higher risk of product contamination from environmental sources (e.g., soil, manure) if production sites lack sophisticated approaches to control contamination (Guerra et al., 2001). In addition, manufacture on farms and in small plants often lacks reproducibility, thus leading to products that may suffer from a lack of consistency for physicochemical parameters ( $\mathrm{pH}$, moisture, and salt), which may act as a hurdle to prevent undesirable bacterial growth (Cole et al., 1990; Adams and Moss, 1995a; Bolton and Frank, 1999; European Commission, 1999; Tienungoon et al., 2000).

São Jorge cheese is a Portuguese cheese that has been produced on the island of the same name in Azores for more than $300 \mathrm{yr}$. This product received a Protected Denomination of Origin, or Appélation d'Origine Controllée, classification in 1984 and is a main source of income for residents of the island. São Jorge cheese is manufactured in small processing plants from raw cow's milk and in the absence of any commercial starter; hence, production does not include a processing step that kills $L$. monocytogenes that may be present in the raw milk. Manufacture includes coagulation at 30 to $31^{\circ} \mathrm{C}$ of whole raw milk following acidification with whey from the previous day's production. Cutting, cooking, and whey draining are followed by hand salting, pressing, and subsequent ripening at 12 to $14^{\circ} \mathrm{C}$ for 4 to 12 mo. Emerging European market rules enforcing stricter quality and safety requirements for rural and artisanal food products, and increasing acceptance of this cheese by consumers and its economic importance for São Jorge inhabitants, make it critical to better understand potential food safety hazards, such as $L$. monocytogenes contamination, that may be associated with the production of São Jorge cheese. The main objective of this study was thus 1) to investigate the prevalence of $L$. monocytogenes in raw milk and cheese randomly collected on São Jorge Island, and 2) to characterize the physicochemical parameters of São Jorge cheese that may affect the growth and survival of $L$. monocytogenes.

\section{MATERIALS AND METHODS}

\section{Sample Collection}

Between July 2002 and May 2003, a total of 105 raw milk samples, 90 curd samples, 96 natural whey starter samples, and 66 cheese samples (obtained after 4 mo of ripening) were collected. All samples were obtained, once a month, from 7 small dairy-processing plants (A through G) that produce São Jorge cheese. Combined, these dairies receive approximately $52,000 \mathrm{~L}$ of raw milk per day in the summer from 273 farmers who deliver milk twice a day (once in the morning and once in the afternoon) in stainless-steel cans without refrigeration. On arrival, the milk is routinely stirred in the can with a milk stirrer and each farmer subsequently transfers the milk into the receiving bulk tank, filtering the raw milk through a white cloth as it is transferred; this white cloth is regularly replaced with a sanitized clean cloth. When the receiving bulk tank is full, all milk is pumped from this tank into the coagulation vat.

At each sampling visit, $200 \mathrm{~mL}$ of raw milk, $200 \mathrm{~mL}$ of whey starter (sampled immediately before addition to the open vat), $100 \mathrm{~g}$ of salted curd, and $200 \mathrm{~g}$ of 4mo-old cheese were aseptically collected and transferred into individual sterile bags or flasks. Samples were transported to Centro de Investigação de Recursos Naturais (Universidade dos Açores, Ponta Delgada, Portugal) in insulated coolers containing cold packs and were analyzed within $10 \mathrm{~h}$ of collection. 
Table 1. Incidence of Listeria monocytogenes in all raw milk, cheese, and curd samples

\begin{tabular}{|c|c|c|c|c|c|c|c|c|c|c|c|c|}
\hline \multirow{2}{*}{$\begin{array}{l}\text { Type of } \\
\text { product }\end{array}$} & \multirow{2}{*}{$\begin{array}{l}\text { Number } \\
\text { of samples } \\
\text { analyzed }\end{array}$} & \multicolumn{11}{|c|}{ Number of positive samples collected in a given month/number of samples collected } \\
\hline & & Jul & Aug & Sep & Oct & Nov & Dec & Jan & Feb & Mar & Apr & May \\
\hline Raw milk & 105 & $1 / 14$ & $0 / 7$ & $0 / 7$ & $0 / 7$ & $0 / 10$ & $0 / 10$ & $0 / 10$ & $0 / 10$ & $0 / 10$ & $1 / 10$ & $0 / 10$ \\
\hline Whey starter & 96 & $0 / 14$ & $0 / 7$ & $0 / 7$ & $0 / 7$ & $0 / 12$ & $0 / 12$ & $0 / 10$ & $0 / 7$ & $0 / 7$ & $0 / 7$ & $0 / 6$ \\
\hline Curd & 90 & $0 / 12$ & $0 / 7$ & $0 / 7$ & $0 / 7$ & $0 / 10$ & $0 / 10$ & $0 / 10$ & $0 / 7$ & $0 / 7$ & $0 / 7$ & $0 / 6$ \\
\hline Cheese & 66 & $0 / 7$ & $0 / 6$ & $0 / 6$ & $0 / 6$ & $0 / 6$ & $0 / 6$ & $0 / 6$ & $0 / 6$ & $0 / 6$ & $0 / 6$ & $0 / 5$ \\
\hline
\end{tabular}

\section{Chemical Analysis}

Subsamples were prepared from all samples to determine $\mathrm{pH}$ using a $\mathrm{pH}$ meter (Hanna Instruments, Padova, Italy); curd and cheese subsamples were used to determine moisture and $\mathrm{NaCl}$ content, as described by James (1999).

\section{Microbiological Analyses}

Sample preparation and $L$. monocytogenes detection were performed as described by Struijk et al. (2001). Briefly, milk, whey, curd, and cheese samples $(25 \mathrm{~mL}$ or g) were aseptically transferred into flasks containing $225 \mathrm{~mL}$ of Listeria enrichment broth base (Oxoid, Basingstoke, Hampshire, UK). Flasks were then placed in a Certomat $\mathrm{H}$ incubator (B. Braun International, Melsungen, Germany), and incubated at $30^{\circ} \mathrm{C}$ with 100 rpm agitation. After 24 and $48 \mathrm{~h}, 0.1-\mathrm{mL}$ aliquots of the enrichments were surface-plated on Palcam agar (Oxoid). After incubation of the plates for $48 \mathrm{~h}$ at $30^{\circ} \mathrm{C}$, 5 Listeria-like colonies (if present) were substreaked on brain heart infusion agar and were presumptively identified by morphology, gram staining, and catalase production.

\section{PCR Analysis}

An L. monocytogenes-specific PCR assay targeting the hemolysin gene ( $h l y A)$ was used, as described by Kabuki et al. (2004), to screen presumptive Listeria colonies to identify L. monocytogenes isolates. Briefly, overnight cultures in brain heart infusion broth of putative Listeria isolates were lysed using lysozyme and proteinase $\mathrm{K}$, and lysates were then used to perform the L. monocytogenes-specific PCR targeting hlyA. Polymerase chain reaction products were separated by gel electrophoresis using a $1.5 \%$ agarose gel; a positive result (i.e., the presence of a PCR product of approximately $860 \mathrm{bp}$ ) indicated that the isolate tested represented L. monocytogenes.

\section{Ribotyping}

Isolates identified as $L$. monocytogenes by PCR were further characterized by automated EcoRI ribotyping, performed using the RiboPrinter Microbial Characterization System (DuPont-Qualicon, Wilmington, DE). Automated ribotyping involved EcoRI digestion of chromosomal DNA, followed by Southern hybridization with an Escherichia coli rrnB rRNA operon probe, as described elsewhere (Bruce, 1996). Images were acquired with a charge-coupled device camera and processed using the RiboPrinter custom software. This software normalizes fragment pattern data for band intensity and relative band position compared with the molecular weight marker, thus providing a high level of reproducibility and standardization. Ribotype patterns were automatically assigned a DuPont ID (e.g., DUP1042) by the RiboPrinter, which was confirmed by visual inspection. If visual inspection indicated that a given DuPont ID included more than one distinct ribotype pattern, each pattern was designated by an alphabetically assigned letter suffix (e.g., DUP-1042A and DUP-1042B represent 2 distinct ribotype patterns within DUP-1042; Gray et al., 2004). Distinct ribotype patterns within a given DuPont ID generally differed by only a position of a single weak band.

\section{RESULTS AND DISCUSSION}

Collection and testing of 357 raw milk, curd, natural whey starter, and cheese samples representing the production chain of São Jorge cheese 1) revealed an overall low prevalence of $L$. monocytogenes, and 2) indicated that, on average, the physicochemical parameters of sampled São Jorge cheese after 4 mo of ripening were likely to minimize the risk of $L$. monocytogenes outgrowth in this cheese.

\section{Prevalence of L. monocytogenes in Cheese and Ingredients}

The overall prevalence of $L$. monocytogenes among 357 raw milk, curd, natural whey starter, and cheese samples, randomly taken and representative of the production chain of São Jorge cheese, was very low. Although neither L. monocytogenes nor other Listeria spp. were detected in whey, curd, or cheese samples, 2 of the 105 raw milk samples analyzed tested positive for L. monocytogenes (Table 1), corresponding to a raw milk 


\begin{tabular}{|c|c|c|c|c|c|}
\hline FSL ID\# & Source & Location & Period & Ribotype & Ribotype image \\
\hline H4-601 & Milk & Azores & 2004 & DUP-1042B & 11 \\
\hline H4-602 & Milk & Azores & 2004 & DUP-1042B & $11 \mid$ \\
\hline J1-116 & $\begin{array}{l}\text { Human } \\
\text { epidemic }\end{array}$ & UK & $\begin{array}{c}1988- \\
1990\end{array}$ & DUP-1042B & | || \\
\hline J1-225 & $\begin{array}{l}\text { Human } \\
\text { epidemic }\end{array}$ & USA (MA) & 1983 & DUP-1042B & $\|$ \\
\hline
\end{tabular}

Figure 1. EcoRI ribotypes for Listeria monocytogenes raw milk isolates and isolates with a matching DUP-1042B ribotype obtained from human patients associated with the listeriosis outbreaks in Massachusetts, United States (1983), and in the United Kingdom (1988 to 1990; Jeffers et al., 2001). FSL = Food Safety Laboratory; DUP = DuPont.

prevalence of $1.9 \%$. No other Listeria species were isolated from the raw milk samples tested. Overall, a total of 40 presumptive Listeria isolates were tested by the L. monocytogenes-specific PCR assay.

Surveys of raw milk collected from farms in different countries found a wide prevalence of $L$. monocytogenes contamination (Adams and Moss, 1995b), ranging from $0.32 \%$ in Germany, to 4.2 and $4.4 \%$ in France and Holland, respectively, up to $7 \%$ in Mexico (Carlos et al., 2001). Kells and Gilmour (2004) reported a $22.2 \%$ prevalence of $L$. monocytogenes in raw milk samples collected in Ireland. Sanchez et al. (1998) reported an incidence of 3.6 and $2.71 \%$ of L. monocytogenes and Listeria innocua, respectively, in raw milk produced in Spain, whereas Guerra et al. (2001) reported a 5\% incidence of $L$. monocytogenes in milk and dairy products sold in mainland Portugal. Therefore, the prevalence levels in São Jorge raw milk and cheese appear to be comparatively low.

In a seroepidemiological study of listeriosis in cows, Boerlin et al. (2002) reported that $11 \%$ of healthy dairy cows in Switzerland simultaneously presented antibodies toward L. monocytogenes listeriolysin $\mathrm{O}$ and internalin A antigens, which are indicative of $L$. monocytogenes infection of the tested cattle. In that study, feeding silage (corn silage, but not grass silage) was found to be a significant risk factor for positive Listeria serology. Cattle breed and hygiene on the farm have also been reported as significant factors associated with a Listeria-positive serological status of animals on a given farm. In addition, a large number of studies have indicated that clinical listeriosis in ruminants is often associated with feeding poor-quality silage (Adams and Moss, 1995b; Driehuis and Oude-Elferink, 2000; Boerlin et al., 2002). Hence, differences in L. monocytogenes incidence for raw milk samples collected in different parts of the world may be related to distinct cattlefeeding practices. The low incidence of $L$. monocytogenes found in our study encompassing raw milk samples collected on São Jorge Island may thus be explained by the fact that cattle in the Azores graze all year round because of the mild climatic conditions (winter temperatures range from 12 to $15^{\circ} \mathrm{C}$ ) and that very little (if any) grass silage is fed to cows on this island. Consistent with this hypothesis, Husu (1990) and Fenlon (1996) also found that it is uncommon for grazing animals to shed detectable levels of $L$. monocytogenes. Broseta et al. (2003) also reported that contamination of raw milk with Listeria is usually more common in the winter, most likely because silage feeding in many parts of the world is more common in that season. In this context, it is important to emphasize that our study included all 4 seasons.

Interestingly, the $2 \mathrm{~L}$. monocytogenes isolated from raw milk shared the same ribotype pattern (DUP1042B, Figure 1), even though they were obtained from raw milk collected at 2 different dairies (Figure 2) and in 2 different months; isolate CM1 was obtained from milk collected in dairy C in July 2002, whereas isolate GM1 was obtained from milk collected in dairy G in April 2003. It should be emphasized that ribotype DUP-

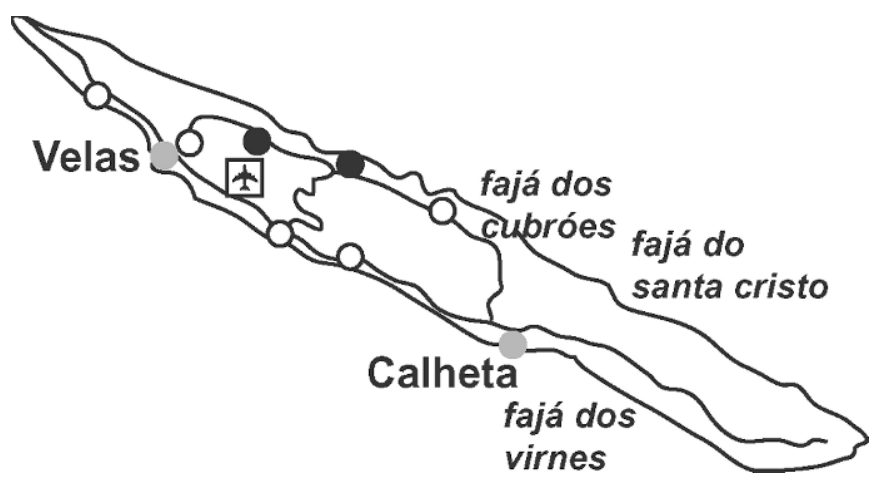

Figure 2. Map of the São Jorge Island showing the locations of the 7 dairy-processing operations included in this study; operations where Listeria monocytogenes was detected in raw milk samples (-); operations without L. monocytogenes-positive samples $(\bigcirc)$. 
Table 2. Physicochemical parameters (mean value \pm SD) for all raw milk, cheese, and curd samples

\begin{tabular}{lllrr}
\hline $\begin{array}{l}\text { Parameter } \\
\text { measured }\end{array}$ & Raw milk & Whey starter & \multicolumn{1}{c}{ Curd } & \multicolumn{1}{c}{ Cheese } \\
\hline $\mathrm{pH}$ & $6.80 \pm 0.15$ & $5.69 \pm 0.51$ & $5.77 \pm 0.19$ & $5.48 \pm 0.20$ \\
NaCl content, $\%$ & $\mathrm{ND}^{1}$ & $\mathrm{ND}$ & $2.55 \pm 0.94$ & $4.73 \pm 0.66$ \\
Moisture, \% & $\mathrm{ND}$ & $\mathrm{ND}$ & $52.25 \pm 5.15$ & $37.79 \pm 3.70$ \\
\hline
\end{tabular}

${ }^{1} \mathrm{ND}=$ not determined.

1042B not only represents a $L$. monocytogenes subtype commonly associated with human listeriosis infections in the United States (Gray et al., 2004), but also has been implicated as the causative subtype of multiple human listeriosis outbreaks, including outbreaks in the city of Boston in 1979 and in the state of Massachusetts in 1983 in the United States, and in the United Kingdom from 1988 to 1990 (Jeffers et al., 2001). Hence, the $L$. monocytogenes subtypes found likely have the potential to cause human disease, highlighting the need for continued efforts to control $L$. monocytogenes contamination of São Jorge cheeses.

\section{Physicochemical Parameters of São Jorge Cheese Limit the Likelihood of L. monocytogenes Outgrowth During Cheese Ripening and Storage}

The ability of $L$. monocytogenes to grow or survive in a food product depends on a variety of physicochemical parameters, including $\mathrm{pH}, \mathrm{a}_{\mathrm{w}}$, and $\mathrm{NaCl}$ content (Conner et al., 1986; Bolton and Frank, 1999; Learson et al., 1999). The average physicochemical parameters associated with São Jorge cheese ripened for 4 mo (Table 2 ) are such that they should limit (if not prevent) the growth of $L$. monocytogenes; the $\mathrm{pH}$ values ranged from a maximum of 5.96 to a minimum of 5.10 , with a mean of 5.48; the salt concentrations ranged from a maximum of $6.30 \%$ to a minimum of $3.20 \%$, with a mean of $4.73 \%$; and the moisture levels averaged $37.79 \%$. Previous studies have specifically shown that $L$. monocytogenes does not grow at a $\mathrm{pH}$ below 5.3 when the $\mathrm{a}_{\mathrm{w}}$ is lower than 0.93 (Tienungoon et al., 2000), or at a $\mathrm{pH}$ below 4.46 regardless of the $\mathrm{a}_{\mathrm{w}}$ (Cole et al., 1990; Farber et al., 1996). In addition, an $a_{\mathrm{w}}$ range between 0.85 and 0.6 (typical for intermediate-moisture foods), which corresponds roughly to a moisture content of 15 to $50 \%$, prohibits the growth of gram-negative bacteria as well as a large number of gram-positive bacteria (Adams and Moss, 1995a).

Although the combination of the average values found for $\mathrm{pH}$, moisture, and salt content should essentially be able to prevent $L$. monocytogenes growth in most São Jorge cheeses, some products representing extreme values (e.g., a $\mathrm{pH}$ of 5.96) may permit growth of this pathogen to some extent. In addition, there is a potential risk for L. monocytogenes initially present in nonrefrigerated raw milk or curd to grow to high numbers when the $a_{w}$ is still very high (i.e., at the beginning of ripening), thus allowing survival of at least some $L$. monocytogenes cells until the end of the natural ripening period.

\section{CONCLUSIONS}

Even though our results indicate that raw milk used for São Jorge cheese production as well as ripened São Jorge cheeses may rarely be contaminated with $L$. monocytogenes, continued efforts to control and monitor the presence of this pathogen in the São Jorge cheese production chain are critical, particularly because physicochemical parameters for some cheeses might permit growth of $L$. monocytogenes. Lack of refrigeration of raw milk in particular represents a potential risk factor that may allow growth of $L$. monocytogenes to high numbers, hence facilitating subsequent survival and persistence in the final cheese. Continued $L$. monocytogenes surveillance, along with the development of risk management strategies and application of the general principles of food hygiene and Hazard Analysis and Critical Control Point guidelines (European Union, 1999; Guerra et al., 2001) should allow successful control of L. monocytogenes in São Jorge cheese manufacture, particularly because the baseline prevalence of this pathogen appears to be low in the cheese production continuum.

\section{ACKNOWLEDGMENTS}

Partial funding for this work was received through a Ph.D. fellowship for author J. M. K., approved by Programa Operacional "Ciência, Tecnologia, Inovação" and Fundação para a Ciência e a Tecnologia (Portugal), with financial co-participation by the European Regional Development Fund (FEDER). We are also indebted to Katy Windham for technical assistance.

\section{REFERENCES}

Adams, M. R., and M. O. Moss. 1995a. The microbiology of food preservation. Pages 98-99 in Food Microbiology. The Royal Society of Chemistry, University of Surrey, Guildford, UK. 
Adams, M. R., and M. O. Moss. 1995b. Bacterial agents of foodborne illness. Pages 186-190 in Food Microbiology. The Royal Society of Chemistry, University of Surrey, Guildford, UK.

Adams, M. R., and L. Nicolaides. 1997. Review of the sensitivity of different foodborne pathogens to fermentation. Food Contr. 8:227-237.

Boerlin, P., F. B. Petzold, and T. Jemni. 2002. Use of listeriolysin O and internalin A in a seroepidemiological study of listeriosis in Swiss dairy cows. J. Clin. Microbiol. 41:1055-1061.

Boggs, J. D., R. E. Whitwam, L. M. Hale, R. P. Briscoe, S. E. Kahn, J. N. MacCormack, J. M. Maillard, S. C. Grayson, K. S. Sigmon, J. W. Reardon, and J. R. Saah. 2001. Outbreak of listeriosis associated with homemade Mexican-style cheese-North Carolina, October 2000-January 2001. Morb. Mortal. Wkly. Rep. 50:560-562.

Bolton, L. F., and J. F. Frank. 1999. Defining the growth/no growth interface for Listeria monocytogenes in Mexican-style cheese based on salt, pH, and moisture content. J. Food Prot. 62:601-609.

Broseta, S. M., A. Diot, S. Bastian, J. Riviere, and O. Cerf. 2003. Estimation of low bacterial concentration: Listeria monocytogenes in raw milk. Int. J. Food Microbiol. 80:1-15.

Bruce, J. 1996. Automated system rapidly identifies and characterizes microorganisms in food. Food Technol. 50:77-81.

Carlos, V. S., R. S. Oscar, and Q. R. E. Irma. 2001. Occurrence of Listeria species in raw milk in farms on the outskirts of Mexico City. Food Microbiol. 18:177-181.

Cole, M. B., M. V. Jones, and C. Holyoak. 1990. The effect of pH, salt concentration and temperature on the survival and growth of Listeria monocytogenes. J. Appl. Bacteriol. 69:63-72.

Conner, D. E., R. E. Brackett, and L. R. Beuchat. 1986. Effect of temperature, sodium chloride, and $\mathrm{pH}$ on growth of Listeria monocytogenes in cabbage juice. Appl. Environ. Microbiol. 52:59-63.

Dalton, C. B., C. C. Austin, J. Sobel, P. S. Hayes, W. F. Bibb, L. M. Lewis, B. Swaminathan, M. E. Procter, and P. M. Griffin. 1997. An outbreak of gastroenteritis and fever due to Listeria monocytogenes in milk. N. Engl. J. Med. 336:100-105.

Driehuis, F., and S. J. W. H. Oude-Elferink. 2000. The impact of the quality of silage on animal health and food safety: A review. Vet. Q. 22:212-216.

European Commission. 1999. Opinion of the Scientific Committee on Veterinary Measures Relating to Public Health on Listeria monocytogenes. European Commission, Health and Consumer Protection Directorate General, Brussels, Belgium.

Farber, J. M., Y. Cai, and W. H. Ross. 1996. Predictive modeling of the growth of Listeria monocytogenes in $\mathrm{CO}_{2}$ environments. Int. J. Food Microbiol. 32:133-144.

Fenlon, D. R. 1996. The incidence and level of Listeria monocytogenes contamination of food sources at primary production and initial processing. J. Appl. Bacteriol. 81:641-650.

Fsihi, H., P. Steffen, and P. Cossart. 2001. Listeria monocytogenes. Pages 751-754 in Principles of Bacterial Pathogenesis. E. A. Groisman, ed. Academic Press, New York, NY.

Gaya, P., J. Sanchez, M. Medina, and M. Nuñez. 1998. Incidence of Listeria monocytogenes and other Listeria species in raw milk produced in Spain. Food Microbiol. 15:551-555.

Guerra, M. M., J. M. McLauchlin, and F. A. Bernardo. 2001. Listeria in ready to eat unprocessed foods produced in Portugal. Food Microbiol. 18:423-429.
Gray, M. J., R. N. Zadoks, E. D. Fortes, B. Dogan, S. Cai, Y. Chen, V. N. Scott, D. E. Gombas, K. J. Boor, and M. Wiedmann. 2004. Listeria monocytogenes isolates from foods and humans form distinct but overlapping populations. Appl. Environ. Microbiol. 70:5833-5841

Husu, J. R. 1990. Epidemiological studies on the occurrence of Listeria monocytogenes in the feces of dairy cattle. J. Vet. Med. B 37:276-282.

James, C. S. 1999. Analytical Chemistry of Foods. Aspen Publishers, Gaithersburg, MD.

Jeffers, T. G., J. L. Bruce, P. L. McDonough, J. Scarlett, K. J. Boor, and M. Wiedmann. 2001. Comparative genetic characterization of Listeria monocytogenes isolates from human and animal listeriosis cases. J. Microbiol. 147:1095-1104.

Kabuki, D. Y., A. Y. Kuaye, M. Wiedmann, and K. J. Boor. 2004. Molecular subtyping and tracking of Listeria monocytogenes in Latin-style fresh cheese processing plants. J. Dairy Sci. 27:2803-2812.

Kells, S., and A. Gilmour. 2004. Incidence of Listeria monocytogenes in two milk processing environments and assessment of Listeria monocytogenes blood agar for isolation. Int. J. Food Microbiol. 91:167-174.

Low, J. C., and W. Donachie. 1997. A review of Listeria monocytogenes and listeriosis. Vet. J. 153:9-29.

Learson, A. E., E. A. Johnson, and J. H. Nelson. 1999. Survival of Listeria monocytogenes in commercial cheese brines. J. Dairy Sci. 82:1860-1868

Linnan, M. J., L. Mascola, X. D. Lou, V. Goulet, S. May, C. Salminen, D. W. Hird, M. L. Yonekura, P. Hayes, and R. Weaver. 1988. Epidemic listeriosis associated with Mexican-style cheese. N. Engl. J. Med. 319:823-828.

Lundén, J., R. Tolvanen, and H. Korkeala. 2004. Human listeriosis outbreaks linked to dairy products in Europe. J. Dairy Sci. 87. (E Suppl.):E6-E11.

Mead, P. S., L. Slutsker, V. Dietz, L. F. McCraig, J. S. Bresee, C. Shapiro, P. M. Griffin, and R. V. Tauxe. 1999. Food-related illness and death in the United States. Emerg. Infect. Dis. 5:840-842.

Nightingale, K. K., Y. H. Schukken, C. R. Nightingale, E. D. Fortes, A. J. Ho, Z. Her, Y. T. Grohn, P. L. McDonough, and M. Wiedmann. 2004. Ecology and transmission of Listeria monocytogenes infecting ruminants and in the farm environment. Appl. Environ. Microbiol. 70:4458-4467.

Pagotto, F., E. Daley, and J. M. Farber. 2002. Enumeration of Listeria monocytogenes in Foods. http://www.hc-sc.gc.ca/fn-an/alt formats/hpfb-dgpsa/pdf/res-rech/mflp74_e.pdf Accessed Aug. 21, 2006.

Ryser, E. T. 1999. Foodborne listeriosis. Pages 39-73 in Listeria, Listeriosis, and Food Safety. 2nd ed. E. T. Ryser and E. H. Marth, ed. Marcel Dekker, New York, NY.

Struijk, C. B., D. A. A. Mossel, and L. M. Browning. 2001. Manual of Validated Standard Operating Procedures for Microbiological Monitoring in Food and Catering Industries. Monograph. Eijkman Foundation for Advanced Medical Microbiological Education and Research in Food and Drinking Water, Utrecht University, Utrecht, The Netherlands.

Tienungoon, S., D. A. Ratkowsky, T. A. McMeekin, and T. Ross 2000. Growth limits of Listeria monocytogenes as a function of temperature, $\mathrm{pH}, \mathrm{NaCl}$, and lactic acid. Appl. Environ. Microbiol. 66:4979-4987. 